\title{
Contribution of Platelet-derived Factor Va to Thrombin Generation on Immobilized Collagen- and Fibrinogen-adherent Platelets
}

\author{
J ac ob J. Briedé ${ }^{1}$, J ohan W. M. Heemskerk ${ }^{1,2}$, Cornelis van 't Veer 3 , \\ H. Coenraad Hemker ${ }^{1}$, Theo Lindhout ${ }^{1}$
}

Depa rtments of ${ }^{1}$ Bioc hemistry, ${ }^{2}$ Human Biology and ${ }^{3}$ Surgery, Cardiova sc ular Research Institute Maastric ht, Maastric ht University, Maastric ht, The Netherlands

\section{Key words}

Fibrinogen, collagen, platelets, platelet factor V, prothrombinase

\section{Summary}

Adhesion of platelets to immobilized collagen induces the expression of anionic phospholipids, e.g. phosphatidylserine (PS), in the outer leaflet of the plasma membrane of these platelets. In contrast, of the platelets that adhere to immobilized fibrinogen only a small sub-population representing $10 \pm 3 \%$ of the total population of the fibrinogenadherent platelets has exposed PS as probed by annexin V binding. Although the presence of PS is thought to be critical for thrombin generation at the platelet surface, no information is available about the effect of this differential PS exposure on the ability of adherent platelets to support thrombin generation. Perfusion of the fibrinogen- or collagen-adherent platelets with solutions containing factor Xa and prothrombin resulted in thrombin generation that i) increased linear during the first perfusion minutes, ii) was about two-fold faster at collagenadherent than at fibrinogen-adherent platelets and iii) was for more than $98 \%$ restricted to the surface of the adherent platelets. It appeared that the lower thrombin generating capacity of fibrinogen-adherent platelets is not due to a lower overall surface density of PS, but is caused by lower amounts of platelet-bound factor Va. Firstly, in both cases thrombin generation could be completely attenuated with antibodies against human factor $\mathrm{Va}$, and secondly, in the presence of an excess of exogenous plasma-derived factor Va similar initial rates of thrombin formation were measured for collagen- and fibrinogen-adherent platelets. Our findings suggest a unique role for immobilized collagen in maintaining haemostasis.

\section{Introduction}

After vessel wall damage, collagen fibers present in the sub-endothelium become exposed to the blood stream. Thrombus formation is initiated by platelets that adhere to these collagen fibers. Interactions between these adherent platelets and other platelets then result in the formation of a haemostatic plug [reviewed in (1)]. At the same time thrombin, a plasma protease, is generated which converts the soluble plasma protein fibrinogen into insoluble fibrin strands. The fibrin network then stabilizes this primary haemostatic plug. Sufficient

Correspondence to: Dr. T. Lindhout, Department of Biochemistry, Maastricht University, PO Box 616, 6200 MD Maastricht, The Netherlands Tel.: +31 43 3881674, Fax: +31 43 3884159, E-mail: t.lindhout@bioch.unimaas.nl amounts of thrombin to accomplish fibrin formation are only generated when the serine protease factor Xa is assembled with the non-enzymatic cofactor $\mathrm{Va}$ at a membrane that contains anionic phospholipids $(2,3)$. In blood, approximately $20 \%$ of the non-activated form of this essential cofactor, factor $\mathrm{V}$, is stored in the alpha-granules of platelets (4) and becomes released and activated when platelets are exposed to a sub-nanomolar concentration of thrombin (5); the other $80 \%$ is found in plasma. Yet, patients with normal plasma factor V levels, but reduced platelet-derived factor $\mathrm{V}$ content, appear to have an increased bleeding tendency $(6,7)$, which might point at an important role of platelet factor $\mathrm{V}$ in maintaining normal haemostasis. It is postulated that the ratio of platelet-derived factor $\mathrm{V}$ over plasma-derived factor $\mathrm{V}$ within a platelet-rich thrombus increases to about 100 -fold (8). The validity of this assumption remains, however, to be proven.

Activated platelets are also an important source of procoagulant anionic phospholipid membranes. In resting platelets negatively charged phospholipids are solely present in the inner leaflet of the plasma membrane, but when platelets in suspension are exposed to a combination of thrombin and collagen they appear at the outer leaflet of the plasma membrane (9). However, whether anionic phospholipids are the sole binding and catalytic sites for the prothrombinase complex at activated platelets is still a matter of debate. Studies that compared the regulation of thrombin generation on synthetic phospholipids with that on activated platelets indicate that in addition to the anionic phospholipid membrane constituents specific receptor-like membrane components for factor $\mathrm{Va}(10)$, factor Xa $(11,12)$ and prothrombin $(13)$ are likely to play a role in prothrombin activation.

We note that in spite of the detailed information that has been gathered on prothrombin activation in platelet suspensions much less is known about the factors that determine thrombin generation at the surface of adherent platelets in a flow-through system. The latter experimental set up is probably more relevant to the in vivo situation. Previous studies from our group have indicated that the procoagulant response of platelets as triggered by adhesion to immobilized fibrinogen and collagen quantitatively differs. Whereas adhesion of platelets to immobilized collagen induced PS exposure and release of P-selectin in the absence of thrombin, these reactions were almost absent in platelets that adhere to immobilized fibrinogen (14). The objective of this study was to assess whether these marked difference in procoagulant responses have consequences for the ability of these platelets to support thrombin generation and if so, whether this could be attributed to a difference in PS exposure or platelet factor $\mathrm{V}$ release and activation. The experimental set up to address these questions consists of a flowthrough system in which washed platelets were adhered to immobilized collagen or fibrinogen prior to their exposure to a flowing buffer containing factor $\mathrm{Xa}$ and prothrombin, but no factor Va. 


\section{Materials and Methods}

Reagents. Bovine serum albumin (BSA), bovine fibrinogen (fraction I, type IV), and apyrase were from Sigma (St. Louis, USA). S2238, a chromogenic substrate for thrombin, was obtained from Chromogenix (Mölndal, Sweden). Human factor Xa and human prothrombin were prepared and quantified as described (15). Human factor Va was kindly donated by Dr. G. Tans, Department of Biochemistry, Maastricht University, Maastricht, The Netherlands. Human $\alpha$-thrombin was prepared as described elsewhere (16). Horm collagen was a product of Nycomed (Munich, Germany). Oregon Green 488labeled annexin V (OG-annexin V) was a product of NeXins Research (Hoeven, The Netherlands). Sheep anti-human factor V IgG and nonimmune purified sheep $\operatorname{IgG}$ were purchased from Kordia (Leiden, The Netherlands). The synthetic peptide $S^{123}$ PGKPGNQNSKNEPP ${ }^{137}$ duplicating the factor Xa binding site of the effector cell protease receptor-1 (EPR-1) (18) and a mouse $\mathrm{mAb}$ directed against this peptide were a kind gift of Dr. N. Senden (Department of Surgery, Maastricht University, Maastricht, The Netherlands). FITClabeled goat anti-mouse IgG was obtained from Molecular Probes (Leiden, The Netherlands).

Isolation of platelets. Suspensions of washed platelets were prepared as described before (14). Briefly, blood was drawn from healthy donors, who had not taken anti-platelet drugs in the preceding two weeks. Platelet-rich plasma was prepared by centrifugation. The platelets were then sedimented from plasma by another centrifugation step, washed twice with HEPES buffer $(10 \mathrm{mM}$ HEPES, $136 \mathrm{mM} \mathrm{NaCl}, 5 \mathrm{mM}$ glucose, $2.7 \mathrm{mM} \mathrm{KCl}, 2 \mathrm{mM} \mathrm{MgCl}_{2}$, pH 6.6), containing $0.5 \mathrm{mg} / \mathrm{ml} \mathrm{BSA}$ and apyrase $(0.1 \mathrm{U} / \mathrm{ml})$. Finally, the platelets were resuspended in HEPES buffer of the same composition, but adjusted to $\mathrm{pH}$ 7.45. Platelets were counted on a Coulter counter (Coulter, Miama, USA), and suspensions were adjusted to $5 \times 10^{7}$ platelets $/ \mathrm{ml}$.

Preparation of fibrinogen- and collagen-coated cover slips with adherent platelet. Fibrinogen-coated glass cover slips were prepared as previously described (19). Cleaned cover slips were exposed for $15 \mathrm{~min}$ at room temperature to $10 \mathrm{mg} / \mathrm{ml}$ fibrinogen in saline solution $(154 \mathrm{mM} \mathrm{NaCl})$. Collagen-coated cover slips were prepared by spraying a solution of $100 \mu \mathrm{g} / \mathrm{ml}$ Horm collagen using a 100-GFX airbrush (Badger, Franklin Park, USA). The collagen-coated cover slips were allowed to dry on air before use. Fibrinogen- and collagencoated cover slips were rinsed and incubated for 15 min with HEPES buffer ( $\mathrm{pH}$ 7.45) to shield uncovered patches of glass with BSA before they were exposed to a platelet suspension. Non-adherent platelets were removed by rinsing 5 times with $250 \mu$ l HEPES buffer ( $\mathrm{pH} 7.45$ ).

Phase contrast and epifluorescence microscopy. A cover slip with adherent platelets mounted in a rectangular flow chamber was placed on the stage of an inverted microscope (Diaphot 200, Nikon, Tokyo, Japan). The images were recorded with a VPM 6132 monochrome high-resolution charge-coupled device camera from Vista (Norbain, UK) that was connected to the arm of a 1:1 beam splitter. Quanticell 900 software (Visitech, Sunderland, UK) was used for analyzing the phase contrast images. Fluorescence images were made using light from a Xenon lamp passing a computer-controlled excitation and neutral density filter wheel, and reaching the objective of the inverted microscope through an UV-transparent liquid light guide and a dichroic long-pass filter. The emission light collected by $40 \times$ quartz oil-immersion objective passed, via the second arm of the 1:1 beam splitter, a computer controlled emission filter wheel, and finally reached a low-light level intensified, charge-coupled device camera working at standard video rate (Photonic Sciences, Robertsbridge, UK). Oregon Green 488 and FITC fluorescence were observed with a $485 \mathrm{~nm}$ excitation filter (bandpass of $40 \mathrm{~nm}$ ), a $505 \mathrm{~nm}$ dichroic long-pass filter, and a $530 \mathrm{~nm}$ emission filter (bandpass of $30 \mathrm{~nm}$ ). Fluorescence images were digitized and averaged after subtraction of background images, and the resulting images were stored. The fluorescence images were off-line analyzed using Quanticell 700 software. Results represent the mean and standard deviation of three experiments.

Thrombin generation. Experiments under flow conditions were performed using a rectangular flow chamber that was described before (19). The flow chamber $(60 \mu \mathrm{l})$, that contained a cover slip with immobilized collagen or fibrinogen, was filled with a suspension of washed platelets and incubated at room temperature for 40 minutes. Non-adherent platelets were removed by rinsing the chamber with HEPES buffer ( $\mathrm{pH} 7.45)$ at a flow rate of $300 \mu \mathrm{l} / \mathrm{min}$ for $10 \mathrm{~min}$. The flow chamber was then perfused $(100 \mu \mathrm{l} / \mathrm{min}$; wall shear rate of 50/s) with HEPES buffer ( $\mathrm{pH} 7.45$ ) containing $3 \mathrm{mM} \mathrm{CaCl}_{2}$, factor Xa, prothrombin and, where indicated, factor Va. Samples $(100 \mu \mathrm{l})$ were collected from the outlet of the flow chamber and added to cuvettes, containing $350 \mu \mathrm{l}$ Tris-EDTA buffer $(50 \mathrm{mM}$ Tris- $\mathrm{HCl}, 175 \mathrm{mM} \mathrm{NaCl}, 20 \mathrm{mM}$ EDTA and $0.5 \mathrm{mg} / \mathrm{ml} \mathrm{BSA}, \mathrm{pH} 7.9$ ) and assayed for thrombin using the chromogenic substrate S2238 as previously described (20). The rate of thrombin generation in the flow reactor, $v_{t}(\mathrm{pmol} / \mathrm{min})$, was calculated from $v_{t}=[\mathrm{IIa}]_{t} \mathrm{Q}$, in which $[\mathrm{IIa}]_{t}$ is the thrombin concentration ( $\mathrm{pmol} / \mathrm{ml}$ ) in the timed sample taken at the outlet of the flow reactor and $\mathrm{Q}$ the volumetric flow rate $(\mathrm{ml} / \mathrm{min})$. To measure thrombin formation in the fluid phase, which could be associated with microparticles, samples of $50 \mu \mathrm{l}$ were collected at the outlet and incubated for an additional $10 \mathrm{~min}$ before Tris-EDTA buffer was added to stop prothrombin activation. The rate of thrombin formation in the fluid phase, $\mathrm{v}_{\mathrm{f}}(\mathrm{pmol} / \mathrm{min})$, was calculated from $v_{\mathrm{f}}=[\mathrm{IIa}]_{\mathrm{f}} \mathrm{V} / \mathrm{t}$ in which $[\mathrm{IIa}]_{\mathrm{f}}(\mathrm{pmol} / \mathrm{ml})$ is the amount of thrombin that was formed during the 10-min incubation time, $\mathrm{V}$ the volume of the flow chamber $(0.06 \mathrm{ml})$ and $\mathrm{t}$ the incubation time $(10 \mathrm{~min})$. The rate of thrombin generation at the surface of the adherent platelets, $\mathrm{v}_{\mathrm{s}}(\mathrm{pmol} / \mathrm{min})$, was then calculated from $\mathrm{v}_{\mathrm{s}}=\mathrm{v}_{\mathrm{t}}-\mathrm{v}_{\mathrm{f}}$.

Statistics. Data are shown as mean \pm SD $(n=3)$ unless otherwise stated.

\section{Results}

Extracellular calcium-induced translocation of anionic phospholipids in the membranes of fibrinogen- and collagen-adherent platelets. Washed platelets in HEPES buffer ( $\mathrm{pH} 7.45$ ) were exposed to fibrinogen- or collagen-coated glass cover slips mounted in a flow chamber as described in "Material and Methods". Platelets in contact with fibrinogen developed pseudopodia, and a majority of them became fully spread. In contrast, platelets in contact with a collagen-coated cover slip all spread. After 40 min of incubation no further morphological changes were observed in both cases. The adherent platelets were exposed to a $\mathrm{CaCl}_{2}$-containing HEPES buffer $(\mathrm{pH} 7.45)$ and platelet shape changes and PS exposure were analyzed by phase contrast microscopy and by the capability to bind OG-annexin V, respectively. In accordance with previous observations (21) most of the platelets did not change in morphology (Fig. 1A), but $10 \pm 3 \%$ of the fibrinogen-adherent platelets responded by vesiculation of the plasma membrane and binding of OGannexin V (Fig. 1B). In contrast, most of the collagen-adherent platelets responded to the addition $\mathrm{CaCl}_{2}$ with a dramatic shape change. Within 10 min the platelets transformed from a fully spread to a balloonshaped appearance (Fig. 1C) and all platelets bound annexin V (Fig. 1D). These data thus confirm our earlier observations (14) that extracellular calcium induces in some fibrinogen-, but virtually all collagen-adherent platelets translocation of PS from the inner leaflet to the outer leaflet of the platelet plasma membrane.

The influence of PS exposure on platelet-dependent thrombin generation. Flow chambers with adherent platelets were perfused at a flow rate of $100 \mu \mathrm{l} / \mathrm{min}$ with HEPES buffer ( $\mathrm{pH} 7.45$ ) containing factor Xa $(0.05 \mathrm{nM})$, prothrombin $(100 \mathrm{nM})$ and $\mathrm{CaCl}_{2}(3 \mathrm{mM})$. Fig. 2A shows that during the first $10 \mathrm{~min}$ of the experiment the rate of thrombin production at the surface of collagen-adherent platelets increased about twofold faster than at the surface of fibrinogen-adherent platelets. However, the steady state rates of thrombin production in the flow chamber with fibrinogen- or collagen-adherent platelets were about the same (1.0 and $1.2 \mathrm{pmol} / \mathrm{min}$, respectively). It is apparent that initially more prothrombinase is assembled at the collagen- than at the fibrinogen-adherent platelets. Yet, the question whether this difference is solely caused by the different overall surface density of PS cannot be answered at this point. One should think of the possibility that part of 
the prothrombinase activity is associated with microparticles shed into the solution by adherent platelets. However, whereas the rate of thrombin production in the chamber increased up to $1 \mathrm{pmol} / \mathrm{min}$, the average rate of thrombin production in the perfusion solution was less than $0.01 \mathrm{pmol} / \mathrm{min}$. It is evident that thrombin production is almost totally confined to the surface of the adherent platelets (Fig. 2A). Alternatively, the overall surface density of PS on fibrinogen-adherent platelets could increase during the time of the experiment because of the platelet activating capability of in situ generated thrombin. However, during thrombin generation no gross increase in the number of annexin V-binding platelets was measured. We found that the percentage of platelets exposing PS in their outer leaflet of the plasma membrane increases from $10 \pm 3 \%$ before thrombin generation to $28 \pm 7 \%$ after 50 min of thrombin production. We recall that in contrast to fibrinogen-adherent platelets, all collagen-adherent platelets bound annexin $\mathrm{V}$ prior to their exposure to in situ generated thrombin.

Dependency of platelet-dependent thrombin generation on platelet factor Va. Because of the absence of exogenous factor $\mathrm{Va}$ in the perfusion solution in the previous experiments, the differential thrombin generating abilities between fibrinogen- and collagen-adherent platelets could be the result of limited amounts of platelet-bound factor Va. To examine this possibility, a similar experiment as shown in Fig. 2A was performed but with added plasma-derived factor $\mathrm{Va}(0.5 \mathrm{nM})$. Fig. 2B shows the rate of thrombin production in flow chambers with collagen- or fibrinogen adherent platelets (closed symbols) and the rate of thrombin production in the perfusion solution (open symbols). It is seen that for collagen-adherent platelets, addition of plasma factor $\mathrm{Va}$ had no effect on the rate of thrombin production (compare Figs. 2A and 2B). In the absence and presence of plasma factor Va the rate of thrombin production linearly accelerated at the same rate $(0.09 \pm 0.02$ and $0.10 \pm 0.01 \mathrm{pmol} / \mathrm{min}^{2}$, respectively). In contrast, addition of plasma factor Va initially accelerated the rate of thrombin generation on fibrinogen-adherent platelets about twofold: from $0.04 \pm 0.01$ to $0.08 \pm$ $0.02 \mathrm{pmol} / \mathrm{min}^{2}$. It is clearly seen in Fig. $2 \mathrm{~B}$ that also in the presence of exogenous factor Va virtually all thrombin produced in the flow chamber originates from the surface of the fibrinogen- and collagen-adherent platelets. Thus, in the presence of plasma factor Va the rate of thrombin generation at the surface of fibrinogen-adherent platelets approaches the rate of thrombin production at the surface of collagen-adherent platelets in the absence of exogenous factor Va.

It is of interest to note that all courses of thrombin generation showed about similar steady state rates of thrombin production. The steady state of thrombin production could result from a transport-limited situation in which the rate of prothrombin activation is faster than the rate at which prothrombin is transported to the catalytic platelet surface. If true, then the steady state rate of thrombin production will depend on the prothrombin concentration in the perfusion solution. In accordance with an earlier observation (19) we found a linear increase in the steady state rate of thrombin production when the prothrombin concentration was increased from 20 to $200 \mathrm{nM}$.

To confirm our notion that platelet-bound factor $\mathrm{Va}$ is critical in factor Xa-catalyzed prothrombin activation, experiments with antihuman factor $\mathrm{V}$ antibodies were performed. Fibrinogen- and collagenadherent platelets were pre-activated for 15 min with human $\alpha$-thrombin $(10 \mathrm{nM})$ to activate platelet factor $\mathrm{V}$. Thrombin was then removed by a 5-min perfusion with $\mathrm{CaCl}_{2}$-containing HEPES buffer ( $\mathrm{pH} 7.45$ ) and the platelets were incubated during $45 \mathrm{~min}$ with $0.4 \mathrm{mg} / \mathrm{ml}$ antifactor V IgG. After unbound antibodies were removed from the flow chamber by flushing for 5 min with $\mathrm{CaCl}_{2}$ containing HEPES buffer, a perfusion was performed with factor $\mathrm{Xa}(0.05 \mathrm{nM})$, prothrombin
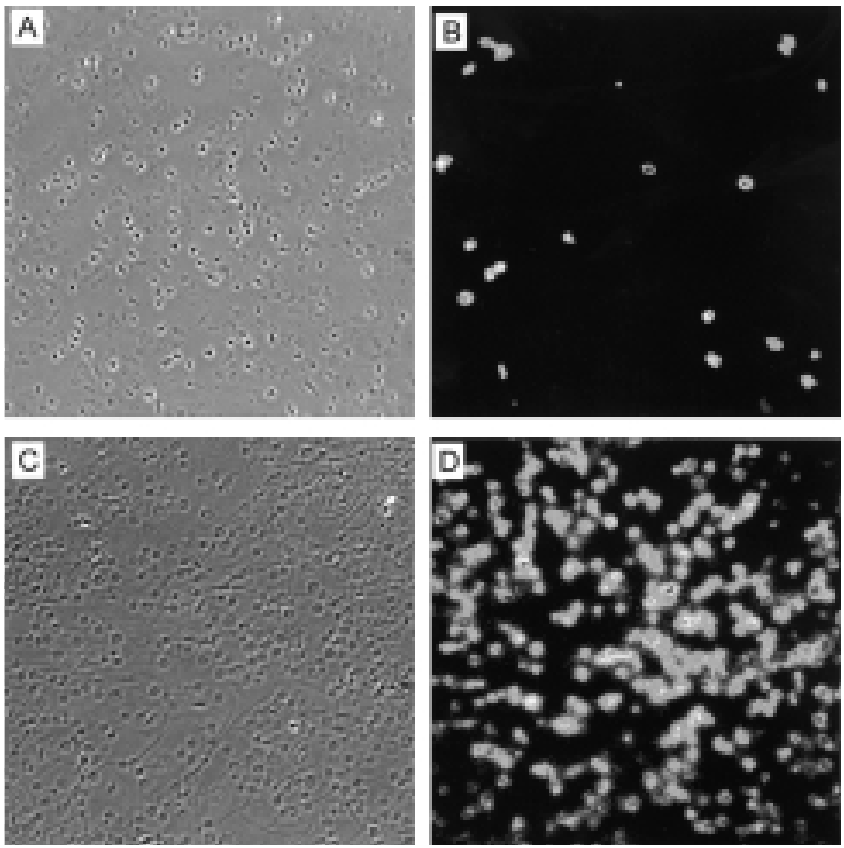

Fig. 1 Morphology and OG-annexin V binding capacity of fibrinogenand collagen-adherent platelets. Washed platelets in HEPES buffer $(\mathrm{pH} 7.45)$ were exposed to immobilized fibrinogen or collagen and incubated with $28 \mathrm{nM}$ OG-annexin $\mathrm{V}$ and $3 \mathrm{mM} \mathrm{CaCl}_{2}$ as described in "Materials and Methods". Panels $\mathrm{A}$ and $\mathrm{B}$ represent phase contrast images and OG-fluorescence images, respectively, of fibrinogen-adherent platelets. Those of collagen-adherent platelets are depicted in panels $\mathrm{C}$ and $\mathrm{D}$. The fibers in panel $\mathrm{C}$ are collagen

$(100 \mathrm{nM})$ and $\mathrm{CaCl}_{2}(3 \mathrm{mM})$. We found that incubation of thrombinactivated fibrinogen- and collagen-adherent platelets with anti-factor $\mathrm{V}$ IgG completely blocked thrombin generation. When the same experiment was performed with purified nonimmune sheep $\operatorname{IgG}(0.4 \mathrm{mg} / \mathrm{ml})$ thrombin generation was comparable with that measured in the absence

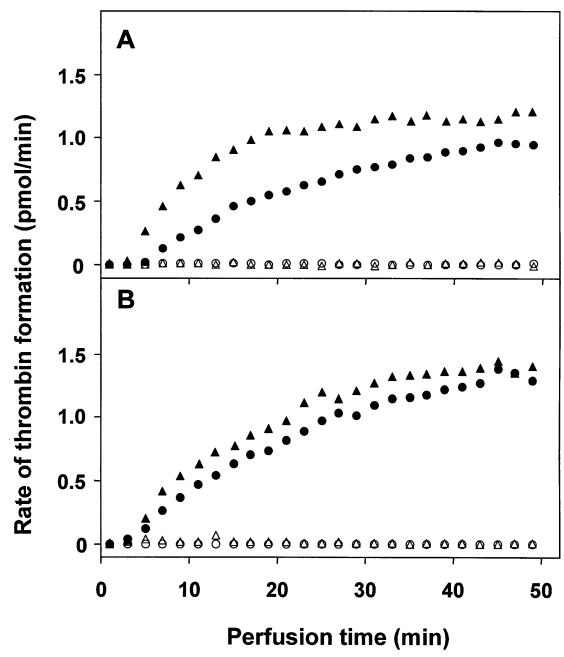

Fig. 2 Thrombin formation on fibrinogen- or collagen-adherent platelets. A flow chamber containing collagen- or fibrinogen-adherent platelets was perfused with HEPES buffer ( $\mathrm{pH} 7.45$ ), supplemented with $3 \mathrm{mM} \mathrm{CaCl}_{2}, 0.05 \mathrm{nM}$ factor Xa, and $100 \mathrm{nM}$ prothrombin in the absence (Panel A) or in the presence of $0.5 \mathrm{nM}$ factor $\mathrm{Va}$ (Panel B). The rate of thrombin generation at the surface of fibrinogen- $(\mathbf{O})$ and collagen-adherent platelets $(\boldsymbol{\Delta})$ was calculated from the rate of thrombin generation in the flow chamber and the rate of thrombin generation in the perfusion solution passing by the fibrinogen- $(\bigcirc)$ and collagenadherent platelets $(\Delta)$ as described in Materials and Methods 

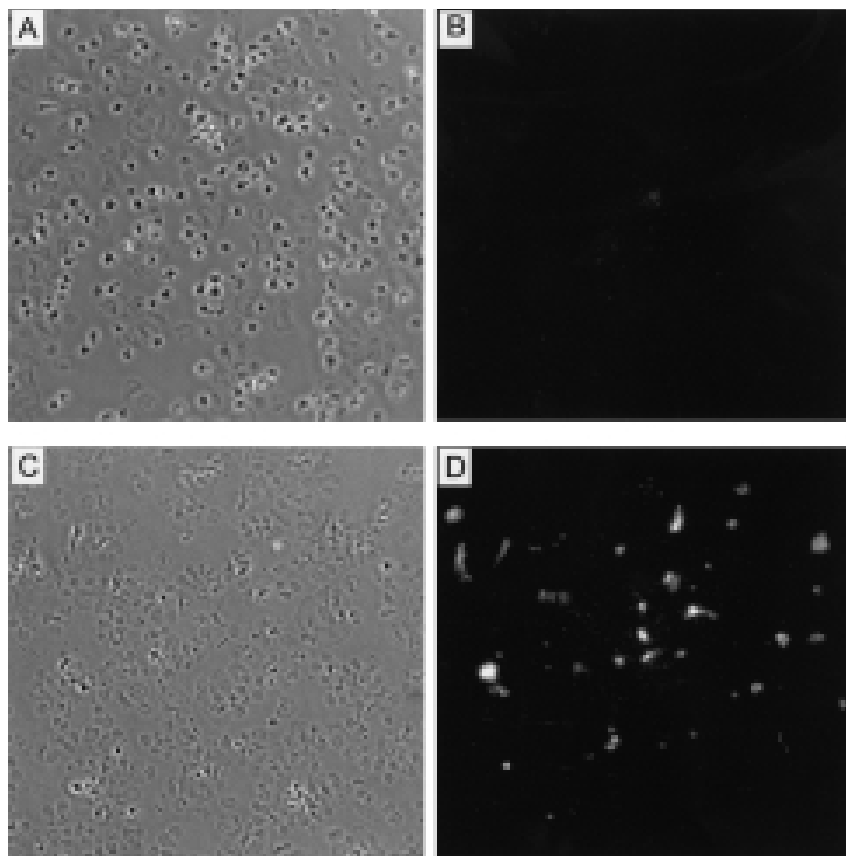

Fig. 3 Binding of anti-EPR-1 monoclonal antibody to unstimulated and thrombin-stimulated fibrinogen-adherent platelets. Platelets were adhered to immobilized fibrinogen, as described in "Materials and Methods". The adherent platelets were incubated with $3 \mathrm{mM} \mathrm{CaCl}_{2}$ in the absence or presence of $10 \mathrm{nM}$ human $\alpha$-thrombin during $15 \mathrm{~min}$. Subsequently, the platelets were incubated with $80 \mu \mathrm{g} / \mathrm{ml}$ mouse anti-EPR-1 mAb. After rinsing, FITC-labeled anti-mouse $\operatorname{IgG}(20 \mu \mathrm{g} / \mathrm{ml})$ was added for $45 \mathrm{~min}$. Excess of the second antibody was removed, and phase contrast as well as FITC-fluorescence images of the same microscopic field were recorded from unstimulated (A and B) and thrombin-stimulated platelets (C and D)

of IgG. To verify that anti-factor V IgG specifically neutralized factor $\mathrm{Va}$ activity thrombin generation, experiments were performed in a well-defined buffer system. The reaction mixture consisted of synthetic phospholipid vesicles composed of $25 \mathrm{~mol} \%$ 1,2-dioleoyl-sn-glycero3-phosphoserine and 75 mol\% 1,2-dioleoyl-sn-glycero-3-phosphocholine $(0.7 \mu \mathrm{M})$, human factor $\mathrm{Va}(0.4 \mathrm{nM}), 1 \mathrm{pM}$ human factor Xa, $200 \mathrm{nM}$ human prothrombin and $3 \mathrm{mM} \mathrm{CaCl}_{2}$ in HEPES buffer, $\mathrm{pH}$ 7.5. Prior to the start of the reaction with prothrombin the reaction mixture was incubated for $45 \mathrm{~min}$ at $37^{\circ} \mathrm{C}$ with either nonimmune sheep IgG $(0.4 \mathrm{mg} / \mathrm{ml})$ or sheep anti-human factor $\mathrm{V} \operatorname{IgG}(0.4 \mathrm{mg} / \mathrm{ml})$. The rate of thrombin generation in the presence of the control $\mathrm{IgG}$ was $2.6 \mathrm{nM} / \mathrm{min}$, whereas no thrombin generation was detectable in the presence of antifactor $\mathrm{V} \mathrm{IgG.}$

Recent studies have indicated that the factor Xa binding site on thrombin-activated platelets could be a heterodimer that consists of factor Va and EPR-1 (11). Although the complete neutralization of platelet factor $\mathrm{Va}$ activity by anti-factor $\mathrm{V} \operatorname{IgG}$ already points at an essential role of platelet factor $\mathrm{Va}$ in the assembly of the prothrombinase complex, it cannot be ruled out that platelet EPR-1 is, by an as yet unknown mechanism, involved in thrombin generation. To detect EPR-1 on the surface of fibrinogen- and collagen-adherent platelets we used a mouse $\mathrm{mAb}$ raised against the peptide $\mathrm{S}^{123}$ PGKPGNQNSKNEPP ${ }^{137}$, which corresponds to the sequence of EPR-1 that interacts with factor Xa and that inhibits prothrombin activation (18). The binding of the monoclonal antibody was visualized utilizing FITC-labeled goat antimouse IgG. Control experiments showed no binding of this fluorescentlabeled antibody in the absence of mouse mAb against the EPR-1 pept- ide $\mathrm{S}^{123}$ - $\mathrm{P}^{137}$. Only after incubation with thrombin $(10 \mathrm{nM})$ a sub-population of fibrinogen-adherent platelets expressed EPR-1 as detected by the mouse mAb against the EPR-1 peptide $S^{123}-P^{137}$ (Fig. 3). Collagenadherent platelets, however, showed expression of EPR-1 prior to their incubation with thrombin (data not shown). In contrast with earlier reports $(11,18)$ we could not detect an effect of the peptide $S^{123}-\mathrm{P}^{137}$ $(10 \mu \mathrm{g} / \mathrm{ml})$ and the mouse mAb against the EPR-1 peptide $S^{123}-\mathrm{P}^{137}$ $(80 \mu \mathrm{g} / \mathrm{ml})$ on cell-surface associated thrombin generation. It is our conclusion that EPR-1 is likely not involved in prothrombin activation at the surface of fibrinogen- or collagen-adherent platelets.

\section{Disc ussion}

The findings of this study indicate that fibrinogen-adherent platelets are less supportive than collagen-adherent platelets in the assembly of the prothrombin-converting enzyme complex. The initially lower rate of thrombin production at the surface of fibrinogen-adherent platelets could be attributed to a lower overall surface density of platelets that have exposed anionic phospholipids. However, in the presence of exogenous plasma-derived factor $\mathrm{Va}$ the initial rate of thrombin production at fibrinogen-adherent platelets approached that found at the surface of collagen-adherent platelets. This finding indicates that the surface density of PS exposing platelets is not necessarily a limiting factor when sufficient amounts of (plasma) factor $\mathrm{Va}$ are available. It is apparent that the amount of factor $\mathrm{V}(\mathrm{a})$ released by fibrinogen-adherent platelets is too low to compensate for the lower PS surface density. This is in well agreement with earlier observations that the secretion reaction is much more pronounced in collagen- than in fibrinogen-adherent platelets (14). In this respect it is interesting to note that in situ formed thrombin had almost no effect on further thrombin formation. That is, the relatively small increase in the number of platelets that had exposed PS during the time course of thrombin generation did not enhance the rate of thrombin generation.

Optimal assembly of the functional prothrombinase complex at synthetic phospholipid membranes requires only the presence of anionic phospholipids. In contrast, several studies indicated the existence of specific membrane proteins that are involved in the assembly of prothrombinase on platelets $(10-13,22)$. In the present study we investigated the role of EPR-1 in platelet-dependent thrombin generation. It was postulated that both EPR-1 and membrane-bound factor Va are required to mediate factor Xa binding to activated platelets to form a functional prothrombinase complex $(11,12)$. We could confirm the critical role of platelet factor $\mathrm{Va}$ in platelet-dependent thrombin generation, but not that of EPR-1. That is, neutralizing antibodies against human factor Va completely blocked thrombin generation when adherent platelets were exposed to the perfusion solution that contained factor $\mathrm{Xa}$ and prothrombin. We also could confirm the presence of EPR-1 at the surfaces of collagen-adherent platelets utilizing a monoclonal antibody against the factor Xa-binding region of EPR-1. In contrast, fibrinogenadherent platelets only expressed EPR-1 when they were activated with thrombin. Thrombin generation at the surface of thrombin activated platelets adhered to immobilized fibrinogen was, however, not inhibited by the monoclonal antibody directed against the factor Xa binding site of EPR-1 nor by the peptide $\mathrm{S}^{123}-\mathrm{P}^{137}$ that duplicates the factor Xa binding site of EPR-1. These results are not compatible with a significant contribution of platelet EPR-1 to the assembly of a functional platelet prothrombinase complex as suggested by others $(11,12)$.

While this work was undertaken, Alberio et al. (23) reported that a single agonist, e.g. thrombin, collagen or ionophore A23187, was unable to produce functionally relevant levels of surface-bound platelet 
factor $\mathrm{V}$ up on incubation with platelets in suspension. However, collagen in conjunction with thrombin did generate a sub-population of platelets, representing $30 \%$ of the total population, that expressed very high levels of surface-bound factor $\mathrm{V}$. In addition, only this very same sub-population of platelets expose PS at their surface. We note intriguing differences between Alberio's and our study. Firstly, this study has demonstrated that virtually all platelets in direct contact with collagen bound annexin V, indicating that all platelets expose PS. Secondly, also fibrinogen-adherent platelets, in spite of the existence of a small sub-population of PS exposing platelets, fully support platelet-dependent thrombin generation when supplied with exogenous factor $\mathrm{Va}$. It is uncertain whether the reported difference between platelets in suspension and those adhered to immobilized collagen are of significant physiological relevance. However, it is of interest to note that adherent platelets apparently do not need a dual stimulation by thrombin to function as sites for the assembly of functional prothrombinase. Collagen-adherent platelets, in addition, apparently have sufficient high levels of surface expressed factor $\mathrm{V}$ to make thrombin generation independent on thrombin-activated plasma factor $\mathrm{V}$. These properties of collagen-adherent platelets could be of critical importance for the developing of a growing thrombus.

\section{Acknowledgement}

We are grateful to Dr. G. M. Willems of the Cardiovascular Research Institute Maastricht for fruitful discussion. This work was supported by Grants 902-26-192 and 902-68-241 from the Dutch Organization for Scientific Rese$\operatorname{arch}(\mathrm{NWO})$.

\section{References}

1. Sixma JJ, Hindriks G, Van Breugel H, Hantgan R, de Groot PG. Vessel wall proteins adhesive for platelets. J Biomater Sci Polym 1991; 3: 17-26.

2. Nesheim ME, Taswell JB, Mann KG. The contribution of bovine Factor V and Factor Va to the activity of prothrombinase. J Biol Chem 1979; 254: 10952-62.

3. Rosing J, Tans G, Govers Riemslag JW, Zwaal RFA, Hemker HC. The role of phospholipids and factor Va in the prothrombinase complex. J Biol Chem 1980; 255: 274-83.

4. Tracy PB, Eide LL, Bowie EJ, Mann KG. Radioimmunoassay of factor V in human plasma and platelets. Blood 1982; 60: 59-63.

5. Baruch D, Hemker HC, Lindhout T. Kinetics of thrombin-induced release and activation of platelet factor V. Eur J Biochem 1986; 154: 213-8.

6. Tracy PB, Giles AR, Mann KG, Eide LL, Hoogendoorn H, Rivard GE. Factor V (Quebec): a bleeding diathesis associated with a qualitative platelet factor V deficiency. J Clin Invest 1984; 74: 1221-8.

7. Janeway CM, Rivard GE, Tracy PB, Mann KG. Factor V Quebec revisited. Blood 1996; 87: 3571-8.

8. Nesheim ME, Nichols WL, Cole TL, Houston JG, Schenk RB, Mann KG, Bowie EJ. Isolation and study of an acquired inhibitor of human coagulation factor V. J Clin Invest 1986; 77: 405-15.

9. Bevers EM, Comfurius P, Zwaal RFA. Changes in membrane phospholipid distribution during platelet activation. Biochim Biophys Acta 1983; 736 : 57-66.
10. Nesheim ME, Furmaniak Kazmierczak E, Henin C, Cote G. On the existence of platelet receptors for factor $\mathrm{V}(\mathrm{a})$ and factor VIII(a). Thromb Haemost 1993; 70: 80-6.

11. Bouchard BA, Catcher CS, Thrash BR, Adida C, Tracy PB. Effector cell protease receptor-1, a platelet activation-dependent membrane protein, regulates prothrombinase-catalyzed thrombin generation. J Biol Chem 1997; 272: 9244-51.

12. Larson PJ, Camire RM, Wong D, Fasano NC, Monroe DM, Tracy PB, High KA. Structure/function analyses of recombinant variants of human factor Xa: Factor Xa incorporation into prothrombinase on the thrombinactivated platelet surface is not mimicked by synthetic phospholipid vesicles. Biochemistry 1998; 37: 5029-38.

13. Byzova TV, Plow EF. Networking in the hemostatic system. Integrin $\alpha_{\mathrm{IIb}} \beta_{3}$ binds prothrombin and influences its activation. J Biol Chem 1997; 272: 27183-8.

14. Heemskerk JWM, Vuist WMJ, Feijge MAH, Reutelingsperger CPM, Lindhout $\mathrm{T}$. Collagen but not fibrinogen surfaces induce bleb formation, exposure of phosphatidylserine, and procoagulant activity of adherent platelets: Evidence for regulation by protein tyrosine kinase dependent $\mathrm{Ca}^{2+}$ responses. Blood 1997; 90: 2615-25.

15. Billy D, Speijer H, Willems G, Hemker HC, Lindhout T. Prothrombin activation by prothrombinase in a tubular flow reactor. J Biol Chem 1995; 270: 1029-34.

16. Schoen P, Lindhout T, Franssen J, Hemker HC. Low molecular weight heparin-catalyzed inactivation of factor Xa and thrombin by antithrombin III: Effect of platelet factor 4. Thromb Haemost 1991; 66: 435-41.

17. Taylor FB, Hoogendoorn H, Chang AC, Peer G, Nesheim ME, Catlett R, Stump DC, Giles AR. Anticoagulant and fibrinolytic activities are promoted, not retarded, in vivo after thrombin generation in the presence of a monoclonal antibody that inhibits activation of protein C. Blood 1992; 79: 1720-8.

18. Ambrosini, GD, Altieri DC. Molecular dissection of effector cell protease receptor-1 recognition of factor Xa. Assignment of critical residues involved in antibody reactivity and ligand binding. J Biol Chem 1996; 271 : 1243-8.

19. Billy D, Briede, Heemskerk JWM, Hemker HC, Lindhout T. Prothrombin conversion under flow conditions by prothrombinase assembled on adherent platelets. Blood Coagul Fibrinolysis 1997; 8: 168-74.

20. Schoen P, Lindhout T, Willems G, Hemker HC. Continuous flow and the prothrombinase-catalyzed activation of prothrombin. Thromb Haemost 1990; 64: 542-7.

21. Briede JJ, Heemskerk JWM, Hemker HC, Lindhout T. Heterogeneity in microparticle formation and exposure of anionic phospholipids at the plasma membrane of single adherent platelets. Biochim Biophys Acta 1999; 1451: 163-72.

22. Hayward CP, Furmaniak Kazmierczak E, Cieutat AM, Moore JC, Bainton DF, Nesheim ME, Kelton JG, Cote G. Factor V is complexed with multimerin in resting platelet lysates and colocalizes with multimerin in platelet alpha-granules. J Biol Chem 1995; 270: 19217-24.

23. Alberio L, Safa O, Clemetson KJ, Esmon CT, Dale GL. Surface expression and functional characterization of alpha-granule factor $\mathrm{V}$ in human platelets: Effects of ionophore A23187, thrombin, collagen, and convulxin. Blood 2000; 95: 1694-702.

Received April 19, 2000 Accepted after resubmission October 30, 2000 